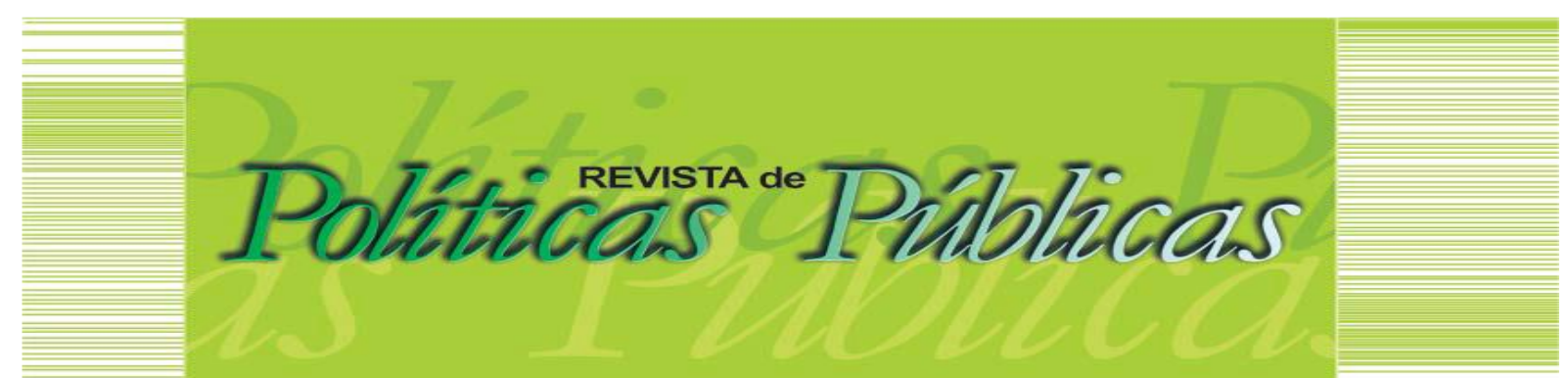

\title{
O PROGRAMA MAIS MÉDICOS E SEUS IMPACTOS NO MERCADO DE TRABALHO MÉDICO DO BRASIL
}

\author{
Gamaliel da Silva Carreiro ${ }^{1}$ \\ Paula Katiana da Silva Carreiro ${ }^{2}$ \\ Antônio Paulino Sousa ${ }^{3}$
}

\section{Resumo}

O presente artigo tem o objetivo de apresentar de forma sistemática os resultados iniciais da pesquisa que analisa os impactos no campo da medicina de algumas políticas públicas implementadas durante os governos de Luís Inácio Lula da Silva e Dilma Rousseff (2003-2016) e que levaram, por um lado, ao aumento substancial do número de vagas e cursos de medicina no Brasil e, por outro, permitiram a entrada sem precedentes de mão de obra médica de outros países para atuar na saúde pública brasileira. A presente reflexão busca responder questões como: Quais as consequências para a classe médica de tão abrupta transformação? Quem se beneficiou com a ampliação da oferta dessa mão de obra no país? Como entender as mudanças no mercado de trabalho médico brasileiro em um contexto de grandes transformações macroeconômicas? E, finalmente, como o campo da medicina está reagindo a essas transformações?

Palavras-chave: Campo da medicina. Transformações. Brasil

\section{THE MORE DOCTORS PROGRAM AND ITS IMPACTS ON THE MEDICAL JOB MARKET IN BRASIL}

\begin{abstract}
The present article aims to presente, in a systematically way, the initial results of the research that analyzes the impacts in the medical field of some public policies implemented during the PT governments (the workers party in Brazil) of Luís Inácio Lula da Silva and Dilma Rousseff (2003-2016), which brought the substantial increase in the number of vacancies and medical courses in Brazil and, on the other hand, allowed the unprecedented entry of medical labor from other countries to act in brazilian public health. The present reflection seeks to answer questions such as: What are the consequences for the medical class of such abrupt transformation? Who benefited from the expansion of this labor supply in the country? How to understand the changes in the brazilian medical labor market in a context of major macroeconomic transformations? At last, how the field of medicine is reacting to these transformations?
\end{abstract}

Keywords: Field of medicine. Transformations. Brazil

Artigo recebido em: 22/09/2020 Aprovado em: 20/05/2021 DOI: http://dx.doi.org/10.18764/2178-2865.v25n1p414-427

\footnotetext{
1 Sociólogo. Doutor em Sociologia pela Universidade de Brasília (UNB). Professor Associado II, do Departamento de Sociologia e Antropologia da UFMA (DESOC-UFMA). Professor do Quadro de Colaboradores do Programa de PósGraduação em Sociologia (PPGS) da Universidade Federal do Maranhão - Campus Imperatriz. Email: gamaliel.carreiro@ufma.br :

${ }^{2}$ Assistente Social. Mestra em Políticas Públicas pela Universidade Federal do Maranhão (UFMA). Assistente Social da Secretaria Municipal de Saúde (SEMUS) do Município de Paço do Lumiar (MA). E-mail: katianapaula@hotmail.com.

${ }^{3}$ Graduação em Filosofia e em Ciências Sociais. Doutor em Sociologia - Université Paris e em Ciências Sociais - Institut Catholique de Paris. Professor Titular da Universidade Federal do Maranhão. E-mail: antonio.paulino@terra.com.br
} 


\section{INTRODUÇÃO}

O Brasil possui poucos ou muitos médicos? Esses profissionais têm qualidade de vida? Fazer um curso de medicina no Brasil e tornar-se um médico é, hoje, sinônimo de ascensão social? Estabilidade financeira? Essas perguntas, quando feitas a uma parcela significativa da população brasileira (senso comum) são facilmente respondidas e a maioria das respostas é positiva. Entretanto, dados colhidos por pesquisadores no país ${ }^{1}$ vêm contrariando tais afirmações, relativizando as imagens que o senso comum possui da profissão de médico e/ou colocando a questão em outros patamares. Respostas bem diferentes estão sendo dadas pelos profissionais formados na área e dados estatísticos colhidos junto à comunidade médica brasileira indicam um mercado de trabalho em rápida transformação, onde certas expectativas como bons salários, vida estável, jornada de trabalho adequada e qualidade de vida não estão se confirmando.

0 presente texto analisa os primeiros resultados de uma pesquisa sobre as transformações no campo da medicina brasileira, as origens de tais mudanças, bem como as tendências em curso. A pesquisa objetiva mapear a situação do campo da medicina e, especialmente do mercado de trabalho desses profissionais no Brasil e no Maranhão nos últimos 20 anos, buscando analisar os impactos de algumas políticas públicas (especialmente o Programa Mais Médico) implementadas durante o período 2003-2016 que tiveram como foco principal a ampliação do número de médicos no Brasil. 0 texto se propõe, ainda, avançar na análise contextualizando as transformações no cenário nacional dentro de uma perspectiva mais ampla da economia global e do mercado de trabalho.

Para o presente artigo, a questão central a ser problematizada pode ser sintetizada como a busca de respostas à seguinte questão: Quais os impactos advindos ao campo da medicina com a implantação de algumas políticas públicas nos governos de Luís Inácio Lula da Silva (2003-2011) e Dilma Rousseff (2011-2016), em especial, o Programa Mais Médico que possibilitou a ampliação do número de médicos formados à disposição tanto do mercado quanto do Estado?

\subsection{Um quadro geral da situação do mercado de trabalho médico no Brasil}

Durante praticamente todo o século XX, os cursos de medicina estiveram concentrados majoritariamente no interior das universidades públicas e o Estado detinha o controle sobre o mercado das profissões. Os cursos da área da saúde, especialmente os de medicina, historicamente tiveram sua abertura mais controlada dos que os demais. A partir da década de 1960, o controle se afrouxa, a 
oferta de vagas é ampliada e a participação das Instituições de Ensino Superior Privadas (doravante, IES) ganham relevância no mercado em todas as áreas. Pesquisas como as de Bueno e Pieruccini (2005), Amaral (2007) e Jatene (2014) informam² um aumento no ritmo de expansão do ensino superior e entre eles o de medicina. Jatene observa que:

Quando entrei no curso de medicina, em 1948, havia no país 13 faculdades, sendo dez federais, duas estaduais e uma privada, a Escola Paulista de Medicina, que mais tarde se federalizou. Daquele ano até 1960 foram criadas mais 17 faculdades - dez federais, três estaduais e quatro privadas - e chegamos a 30 escolas de medicina. De 1961a 1979, o que inclui o período da revolução, criamos mais 47 , com uma particularidade: 26 eram privadas, sendo que a maioria era dirigida por instituições que não tinham nenhuma tradição no setor de saúde e inclusive não dispunham de hospital universitário. No período seguinte, até 1996, houve uma parada na criação de escolas, porque o número excessivo gerou reações de entidades como a Associação Médica Brasileira e o Conselho Federal de Medicina. Nesse intervalo, as únicas escolas novas foram uma federal em Rondônia, uma estadual no Paraná e três privadas - em Blumenau (SC), Alfenas (MG) e Taubaté (SP). Em 1996 tínhamos, portanto, 82 faculdades de medicina. E daquele ano até 2011 abrimos mais 103, com uma particularidade: mais de $50 \%$ eram privadas, com os mesmos defeitos das anteriormente criadas. Em 2012, no dia 5 de junho, o governo autorizou mais nove faculdades privadas, além de 18 novos cursos em universidades federais. Ficamos, assim, com 63 federais, 27 estaduais, 7 municipais e 115 privadas, num total de 212 faculdades de medicina. (JATENE, 2014, 79-80).

Os dados oficiais disponibilizados pelo $\mathrm{MEC}^{3}$ em 2018 nos informam que em menos de cinco décadas, o total de médicos no Brasil aumentou $665,8 \%$, índice muito maior do que 0 crescimento total da população do país, que foi de $119,7 \%$.

Foi a constituição de 1967 imposta pelo regime militar que permitiu o capital privado entrar com mais força na educação superior. O governo eliminou a vinculação orçamentária para a educação, aumentando a participação privada na oferta do Ensino Superior por meio de incentivos governamentais e autorizações de funcionamento emitidas pelo Conselho Federal de Educação da época. Desde então, a participação das IES privadas na formação de novos quadros profissionais só aumentou no país. Se dermos um salto até a década de 1980, perceberemos importantes alterações na legislação, especialmente na constituição de 1988 que ampliaram a presença das IES no mercado do Ensino Superior. De 1988 a 2007 foram abertos, aproximadamente, 93 cursos de medicina, sendo 65 deles em IES privadas. Importa destacar que em 1996 é promulgada a nova Lei de Diretrizes e Bases da Educação (LDB) e a partir dela, o Ministério da Educação (MEC) criou novos incentivos e regulamentação favorável ao Ensino Superior Privado, dando novo fôlego ao capital privado ampliar sua presença no mercado da educação superior.

Se tomarmos só os cursos de medicina como exemplo, veremos um processo contínuo no crescimento da oferta de vagas no país. Os dados disponibilizados pelo MEC (2018) informam que entre 2003 e 2015 o número de faculdades de medicina privadas passou de 64 para 154; as unidades públicas subiram de 62 para 103. No final de 2017, o país já possuía 303 cursos de medicina dos quais $30 \%$ foram 
abertos a partir de 2013 graças à nova legislação. Esse número é o dobro do americano, que em 2016 era de 145. Somente no ano de 2016, o MEC autorizou a abertura de novos cursos de medicina em 37 municípios brasileiros, perfazendo um total de 2355 novas vagas ${ }^{4}$. Importa salientar que a expansão dos cursos de medicina acompanha o processo de expansão do ensino superior como um todo capitaneado pelas IES privadas. A novidade aqui é o ritmo de crescimento dos cursos de medicina que, embora tenha começado acanhado na década de 1960, se intensifica a partir de 2003.

Em 2015, o Brasil já contava com 432.870 registros de médicos, o que correspondia à razão nacional de 2,11 médicos por grupo de 1.000 habitantes. Em 2017, esse número pulou para 451.777 registros e, segundo Scheffer (2018), em janeiro de 2018 já eram 491.468. A taxa brasileira fica próxima de países como Estados Unidos (2,5), Canadá $(2,4)$ e Japão $(2,2)$. Em termos de comparações globais, os dados brasileiros são melhores do que os do Chile $(1,6)$, China $(1,5)$ e Índia $(0,7)($ Scheffer, 2015 , 2018).

Em 2015, o Brasil possuía uma taxa de 10,21 diplomados (recém-formados) em medicina por grupos de 100 mil habitantes, uma taxa próxima da encontrada nos países-membros da Organização para a Cooperação e Desenvolvimento Econômico (OCDE), que na época era de 10,56. O indicador brasileiro é maior do que o de países como Suíça $(9,4)$, Espanha $(9,0)$, Estados Unidos $(6,5)$ e França $(6,0)$ (SCHEFFER, 2015).

\subsubsection{O Programa Mais Médico}

Números tão expressivos como estes (aparentemente tão bons, quando vistos isoladamente) estão diretamente relacionados com uma série de decisões do poder executivo nacional, em especial, durante os governos de Luís Inácio Lula da Silva e Dilma Rousseff (2003-2016) que criaram e/ou redimensionaram algumas políticas públicas. Merece destaque aqui o Programa Mais Médico. Não é objetivo do presente artigo, um debate aprofundado sobre esse Programa, entretanto, a sua implantação teve efeitos importantíssimos sobre as novas configurações do mercado de trabalho médico no Brasil, Senão, vejamos: foi a Medida Provisória $n^{0}$ 621, da então presidente da República, Dilma Rousseff, que lançou o Programa Mais Médicos. O Programa previa uma série de mudanças visando à melhoria do atendimento aos usuários do SUS, entretanto suas consequências extrapolam em muito os objetivos inicialmente programados. A medida, posteriormente convertida na Lei $n^{0}$ 12.871, de 22 de outubro de 2013, estabeleceu articulação entre os três níveis da federação (Governo Federal, Estados e Municípios) e outras parcerias com ações de formação de recursos humanos na área médica para o SUS (BRASIL, 2013). O Programa Mais Médicos tinha como ambição os seguintes objetivos: 
I. diminuir a carência de médicos nas regiões prioritárias para o SUS, a fim de reduzir as desigualdades regionais na área da saúde;

II. fortalecer a prestação de serviços na atenção básica em saúde no país;

III. aprimorar a formação médica no país e proporcionar maior experiência no campo de prática médica durante o processo de formação;

IV. ampliar a inserção do médico em formação nas unidades de atendimento do SUS, desenvolvendo seu conhecimento sobre a realidade da saúde da população brasileira;

V. fortalecer a política de educação permanente com a integração ensino-serviço, por meio da atuação das instituições de educação superior na supervisão acadêmica das atividades desempenhadas pelos médicos;

VI. promover a troca de conhecimentos e experiências entre profissionais da saúde brasileiros e médicos formados em instituições estrangeiras;

VII. aperfeiçoar médicos para atuação nas políticas públicas de saúde do país e na organização e funcionamento do SUS; e

VIII. estimular a realização de pesquisas aplicadas ao SUS (BRASIL, 2013).

O Programa visa, de maneira geral, promover melhorias na infraestrutura das UBS, mudanças na formação dos estudantes de Medicina, ampliação da oferta de vagas de residência médica e provimento emergencial de médicos para atuar em todas as regiões do país, sobretudo naquelas onde há maior vulnerabilidade, dificuldade de fixação desses profissionais e problemas de acesso da população à atenção básica. Nesses termos, o desenho do programa envolve três ações simultâneas de curto, médio e longo prazo, complementares entre si para atingir os objetivos supramencionados: 1) A ampliação da oferta de cursos de Medicina e de vagas para residência médica; 2) $O$ estabelecimento de novos parâmetros para a formação médica no país e 3) A promoção de "aperfeiçoamento de médicos na área de atenção básica em saúde, mediante integração ensinoserviço, inclusive por meio de intercâmbio internacional" (BRASIL, 2013) o que, na prática, significou o provimento emergencial de médicos para a atenção básica no SUS.

Interessante observar que o programa foi objeto de intensa crítica, sobretudo da classe médica, por um subitem que foi pensado como estratégia para suprir, de maneira temporária e emergencial, a escassez desses profissionais nas regiões de maior vulnerabilidade do país. Entretanto, não foram as medidas de curto prazo (importar médicos de cuba) que alteraram o jogo de forças entre o Campo da medicina, o Estado e o Capital, mas as de médio e longo prazo, dentre elas, a principal foi a de ampliação do número de faculdades de medicina e de vagas nos cursos já existentes que atualmente estão lançando milhares de novos profissionais no mercado, em um processo de difícil retrocesso.

Assim, se é possível apontar uma tendência no Brasil, sobretudo no período 2003-2016, mas, especialmente, a partir de 2010 , foi a de ampliação do número de médicos formados atuando no Brasil. Scheffer (2018) mostrou que nunca houve um crescimento tão grande da população médica no Brasil num período tão curto de tempo. Em 2016 se formaram 21,106 médicos e se a política pública do Programa continuar no mesmo ritmo poderá chegar a mais de 28 mil, em 2024, como resultado das metas de médio e longo prazo do Programa. Importa agora entender algumas das razões que levaram 
o Governo Federal a flexibilizar e facilitar a abertura de novos cursos e, por outro, atrair mão de obra médica estrangeira para o Brasil.

\section{EMBATES ENTRE O CAMPO DA MEDICINA, O ESTADO E CAPITAL}

Foi a constituição de 1988 (BRASIL, 1988) que elevou o direito à saúde à categoria dos direitos fundamentais, por estar interligado ao direito à vida e à existência digna. Tal direito representa um dos fundamentos da República Federativa do Brasil, sendo considerado pela doutrina jurídica e legislação uma obrigação do Estado e uma garantia de todo o cidadão. É diante desse contexto que importa compreender os embates entre o Estado com suas obrigações sociais e suas políticas públicas por um lado, o campo da medicina e os interesses de classe que ele defende e o capital privado, aqui representado pelos agentes econômicos atuantes nos grandes hospitais e clínicas, nos planos de saúde e os donos das IES privadas formadoras de mão de obra médica e empregadores.

Se tomarmos como exemplo apenas a relação entre o Estado e o campo da medicina, perceberemos uma série de alterações importantes nas últimas décadas. Segundo Pierantoni e Viana (2003), há pelo menos, três décadas, percebe-se um importante debate sobre quais as melhores estratégias para a implementação de políticas de saúde mais eficientes no Brasil. A título de exemplo, Amaral (2007) observa que desde 1995 a Organização Mundial de Saúde (OMS) vem propondo uma reorientação para os cursos de medicina no mundo e no Brasil que atenda de forma mais efetiva as necessidades sociais. Segundo o supracitado autor, apesar do esforço da OMS, poucos resultados têm sido apresentados, sobretudo no que tange às melhorias dos sistemas de saúde 5 . Uma das conclusões do relatório da OMS sobre os cursos de medicina, por exemplo, indica que:

\footnotetext{
Apesar de as EM (Escolas de Medicina) serem fundamentais no sistema de promoção à saúde para as comunidades, estas têm sido pouco ativas em avaliar as prioridades de saúde e em organizar programas de pesquisa e ensino que produzam melhorias no funcionamento do sistema de saúde, e em última análise nas condições de saúde da população. Concluem, também, que as EM têm missões bem definidas e compromissos institucionais de servir às populações, mas que há uma grande disparidade entre 0 discurso teórico e a prática. (AMARAL, 2007. p. 22).
}

Com a implantação dessa política pública que possibilitou aumentar exponencialmente 0 número de médicos formados no país, em curto espaço de tempo, o Governo Federal redimensionou o jogo de forças não apenas entre médicos e o Estado, mas também entre esta classe de profissionais e o capital privado que compra sua mão de obra no mercado. E quando se olha para a situação do mercado de trabalho das grandes metrópoles brasileiras, em especial as capitais, o cenário da oferta e procura por mão de obra médica é bem diferente do encontrado nas pequenas cidades. Assim, 


\section{O PROGRAMA MAIS MÉDICOS E SEUS IMPACTOS NO MERCADO DE TRABALHO MÉDICO DO BRASIL}

enquanto a taxa de médico no interior do país chegava a 1,28 médicos por grupo de mil habitantes, nas capitais esse número chegava a 5,07 em 2018 (SCHEFFER, 2018). No Estado do Maranhão, o que possuía a menor densidade de médicos, (0,87 médicos/mil habitantes) vive uma situação de ter em sua capital a razão de 4,05 médicos por grupo de mil habitantes. Esse número é superior aos 2,7 encontrados no Reino Unido que serviu como referência para a criação do Programa Mais Médico. Em outras capitais, essa proporção é ainda maior. Vitória, por exemplo, a taxa de médico por população de mil habitantes era de 12,27, em Porto Alegre e Florianópolis acima de 9 e Recife, Belo Horizonte e Goiânia, acima de 6 (SCHEFFER, 2018 ). Embora os dados devam ser analisados tendo como referências outras variáveis (como, especializações em determinadas áreas com maior demanda), apontam para uma mudança importante na relação da oferta e procura por serviços médicos no país como um todo. Em especial, o Estado e o Capital Privado, representado pelos grandes hospitais e planos de saúde, como principais compradores dessa mão de obra, são os principais beneficiários, podendo negociar e reduzir os valores pagos pelos serviços médicos, e é o que está ocorrendo.

As pesquisas na capital maranhense, e não parece ser diferente do restante do país, nos informam um processo de redução dos valores pagos pelos serviços médicos seja no âmbito dos contratos públicos seja no âmbito das empresas privadas. Esse não é um fenômeno exclusivo desse segmento do mercado de trabalho, já o vimos atingir outras profissões no Brasil nos últimos 30 anos como a classe de enfermeiros, nutricionistas, farmacêuticos, dentistas e advogados, só para indicar algumas. Ela pode ser compreendida e apreendida teoricamente dentro do que Polany (2004) categorizou de "Grande Transformação". É sobre ela que nos dedicaremos nas próximas páginas, objetivando retomar algumas reflexões para a compreensão macrossociológica do fenômeno em questão.

Teoricamente, as categorias profissionais se ajustam às transformações históricas do processo de produção econômica e a estrutura econômica determina o espaço que cada categoria deve ocupar na estrutura da sociedade. Ora, diante das transformações econômicas e cognitivas (LEBARON, 2010) pela qual a nossa sociedade está passando, qual é o espaço que os médicos ocupam na estrutura da sociedade? O que nos permite elaborar esse problema é o fato de que as pesquisas mais recentes sobre as transformações indicam que existe uma tendência de aumento das desigualdades sociais e um retorno a condições salariais semelhantes às encontradas no século XIX (PIKETTY, 2014; DUBET, 2015). O problema central é relativo à renda do trabalho e as formas de distribuição da riqueza.

Essas transformações atingem também categorias profissionais como os médicos, que ao longo de praticamente todo o século XX estiveram fora dessa pressão do capital, especialmente no Brasil. É bem verdade que no início século XX os médicos tinham relações diretas com os pacientes e 
o processo de trabalho era mais artesanal e baseado na autonomia. Essa característica da assistência à saúde, começa a se transformar no Brasil, sobretudo a partir dos anos 1980, com o processo de produção capitalista e a saúde passa a ser considerada como uma mercadoria fictícia no sentido de Karl Polanyi. A valorização social e monetária dessa mercadoria reifica progressivamente o trabalhador da área médica. Nesse sentido, os médicos passaram a se submeter às regras de produtividade impostas às demais categorias profissionais de qualquer empresa tal como: a instabilidade no emprego, ritmo intenso de trabalho, mão de obra em expansão no mercado, precarização das condições de trabalho, insalubridade, futuro incerto, etc, e tudo isso sem considerar a natureza e as particularidades do trabalho médico que visa limitar a dor e o sofrimento.

Na dinâmica do capitalismo existe uma pluralidade de formas de valorizar as coisas transformando-as em mercadorias obedecendo à lógica da acumulação ilimitada do capital e, para isso, o capital se desloca em diferentes campos em busca da lucratividade. Essa forma de deslocamento tem por efeito ampliar e harmonizar o universo da mercadoria. As exigências de lucro orientam as transformações e por essa razão os limites atingidos pelos lucros relativos da produção de massa estimularam o deslocamento do capitalismo em direção a novas áreas que ficaram à margem, enquanto a produção em massa era considerada como espaço privilegiado de lucro. Esse tipo de produção supõe fortes investimentos em capital e a mobilização de um grande número de trabalhadores a quem é necessário pagar salários. Assim, há uma homologia entre a produção capitalista de massa e o desenvolvimento considerável da sociedade salarial (BOLTANSKI; ESQUERRE, 2017, p. 375-376). É nesse sentido que se desenvolve no campo da medicina um tipo de trabalho médico em grande escala onde a organização disciplinada pela lógica da produtividade assume um papel central nos novos modos de dominação no campo da medicina (BOURDIEU, 1987, 2004).

Para compreender a atual lógica de expansão do capitalismo e como os médicos são afetados, é preciso levar em conta os limites impostos pela busca da lucratividade na produção em massa. Como bem observa Boltanski e Esquerre (2017), o modelo de deslocamento das empresasem direção aos países com baixos salários têm por objetivo reduzir os custos da produção e manter a margem de venda e de lucro. Entretanto, tem algo novo acontecendo, pois a lógica da nova economia do enriquecimento procura captar menos dinheiro dos pobres, o que foi estimulante na produção de massa, ao contrário a maximização do lucro passa a ser buscada nas categorias liberais como os médicos através do processo de controle da profissão, do assalariamento da classe médica e do monopólio do mercado de assistência à saúde. "É a extensão do campo da mercadoria que alimenta o desenvolvimento de uma economia do enriquecimento". (BOLTANSKI; ESQUERRE, 2017, p.379) 


\subsection{A lógica da produtividade imposta à classe médica}

A institucionalização do sistema de mercado consolidou e desenvolveu progressivamente uma forma particular de organização do trabalho que atingiu também o trabalho do médico. Isso marca uma nova fase de desenvolvimento do capitalismo ao instituir o modelo de industrialização definido pela produção e pelo consumo de massa e uma nova arte de governar (POLANYI, 2004). Com a crise do modelo keynesiano um novo modelo de organização do trabalho se instaura com o neoliberalismo que se caracteriza por um controle sistemático de avaliação de desempenho baseado na produtividade.

A concentração da força de trabalho da saúde e dos equipamentos em um único espaço que é o hospital, a tecnificação do ato médico e a ênfase na medicina curativa são elementos centrais dessa transformação. A transformação da saúde em mercadoria tornou possível também implantar um novo tipo de governabilidade e gerenciar os que produzem essa mercadoria fictícia que são os médicos. O hospital torna-se o espaço privilegiado de organização do trabalho e da produtividade dos médicos.

\footnotetext{
Com o reordenamento do trabalho médico, a dimensão científico-tecnológica da medicina tornou-se predominante, orientando global ou parcialmente os processos de trabalho atuais e impondo um novo padrão de formação escolar, ancorado na estrutura altamente tecnificada do hospital-escola, valorizado por meio de mecanismos formais e informais a aquisição de conhecimentos científicos e a integração ao mercado de trabalho através da especialização (NASCIMENTO SOBRINHO, NASCIMENTO E CARVALHO, 2005, p. 131-132).
}

As transformações recentes do trabalho do médico estão associadas à grande transformação do sistema de produção capitalista que atinge as agências privadas e as políticas públicas de saúde. É o controle sobre a clientela, a propriedade privada dos meios materiais de trabalho e a liberdade de mercado em relação à fixação do preço (da consulta e do tratamento) que permite compreender a posição que o médico ocupa na estrutura do campo da medicina e a questão da autonomia da prática médica.

\footnotetext{
Mudanças ocorridas no modo de produção do cuidado médico promoveram crescente separação entre o produtor direto e uma parcela significativa de seus meios de produção, e a substituição da troca entre produtor e consumidor pela venda da força de trabalho, no âmbito de um sistema de produção estatal ou provado dos serviços de saúde. (NASCIMENTO SOBRINHO, NASCIMENTO E CARVALHO, 2005, p.133).
}

Essas transformações modificaram as formas de inserção do médico no mercado de trabalho na medida em que este é caracterizado por uma perda progressiva da autonomia profissional e isso tem consequências no ponto de vista não somente do stress para o médico, mas também na qualidade do serviço prestado à população (SCHRAIBER, 1993; MENDES, 1986). As pesquisas iniciadas na capital maranhense em 2019, com médicos, apontam para a consolidação de um modelo 
de trabalho marcado pelo produtivismo ao qual o profissional dificilmente pode se opor. 0 depoimento de uma médica atuante na rede privada ilustra

\begin{abstract}
Nós temos que atender, no mínimo 04 pacientes por hora e o hospital queria que fosse 05 , mas nós resistimos. Ora, dependendo do paciente a elaboração do diagnóstico é um pouco mais demorada, sobretudo quando se trata de pessoas idosas. Nesse caso é necessário um pouco mais de tempo para se diagnosticar (Entrevista com médica S. A J. São Luís, 13/06/2019).
\end{abstract}

Embora tenhamos encontrado na pesquisa profissionais que recusam a se curvar ao produtivismo e lutam por autonomia e por um estilo de trabalho mais humanizado, personalizado sem metas diárias de atendimento a serem cumpridas, o produtivismo é um fato estabelecido tanto na rede pública quanto na privada, e a pressão pelo aumento da produtividade diária dos profissionais é um fato. É a certeza da existência de um importante e crescente exército industrial de reserva para substituir o profissional que se recusa a se submeter às novas condições de trabalho, fato mais constante nas grandes cidades brasileiras, que possibilitam essa nova postura do Estado e das grandes empresas frente à classe médica.

0 modo de inserção do médico no mercado de trabalho foi classificado em cinco categorias na pesquisa pioneira de Donnângelo (1975) ainda na década de 1970, na cidade de São Paulo. São elas: autônomos típicos; autônomos atípicos, assalariados; empresários e trabalhadores autônomos com contratação precária. 0 que acontece com frequência, como observado pela supracitada autora, é a combinação de várias formas de inserção. Já na década de 1970, Donnângelo percebe fortes indícios de um processo de assalariamento dos médicos em São Paulo. A tendência observada por Donnângelo, na década de 1970, aparecerá com maior intensidade na pesquisa de Machado (1997), vinte anos depois. Machado verificou a intensificação do processo de assalariamento, redução da remuneração e a multiplicidade de vínculos como padrão de empregabilidade dos médicos. Para garantir a manutenção da renda, constatou uma elevada participação em plantões semanais como formas de trabalho, além da informatização das relações de trabalho. A tendência percebida por Machado em 1997 se acentuou no período 2010-2016, conforme pesquisas de Scheffer (2010, 2015, 2017). Na capital maranhense, os primeiros dados analisados por nós dão conta de processos semelhantes, tais como: 1) Diminuição dos valores pagos na rede pública aos plantões médicos 2) A elevação da participação desses profissionais em plantões na rede privada 3) múltiplos vínculos de trabalho 4) os grandes hospitais privados exigindo a transformação do profissional em pessoa jurídica para poder ser contratado e assim, evitar despesas com direitos trabalhistas, 5) Avanço dos processos de informatização em determinadas especialidades, sobretudo na terceirização da produção de laudos médicos em outros centros urbanos, onde a mão de obra é mais barata, tendo como consequência a diminuição dos custos. 


\section{UMA GUISA DE CONCLUSÃO}

O presente artigo apresentou de maneira sucinta uma sistematização dos resultados iniciais da pesquisa iniciada em 2018 sobre os impactos no campo da medicina de algumas políticas públicas que permitiram a ampliação da mão de obra médica no Brasil, principalmente no período 2012-2016. Obviamente ainda há muito que pesquisar e refletir. Importantes temas ainda carecem de mais análise, mais pesquisa e mais reflexão adensada.

Embora o jogo de forças atual pareça extremamente prejudicial à classe médica, no sentido de perdas significativas de direitos, "privilégios", autonomia profissional, diminuição de salários, aumenta da jornada de trabalho, etc, o futuro não está dado, não é certo. A história não caminha por uma via de mão única. 0 imponderável sempre está presente, o imprevisível é uma constante e não pode ser subtraído da presente análise. A título de exemplificação destacamos um fato importante acorrido em 2018 que serve como alerta da presença do imponderável, melhor dizendo, da reação normal que se espera de um campo sob forte pressão. Com o impeachment de Dilma Rousseff e a consequente subida ao poder de Michel Temer em 2016, novas direções para essa política pública de expansão dos cursos de medicina foram dadas. No final de 2017, o governo sinalizou com a suspensão da abertura de cursos de medicina e, atendendo ao lobby médico, em 05 de abril de 2018 o Ministério da Educação publicou as PORTARIAS № 328 e 329 de 5 de abril de $2018^{6}$, implantando uma moratória de, pelo menos, cinco anos para os cursos de medicina e dificultando a abertura de novos cursos após essa data.

A decisão atendeu a reivindicação do CFM e de entidades ligadas ao Campo da medicina no país, que passaram a pressionar o então presidente Temer e o MEC a rever a política pública de expansão de cursos de medicina no país, implementada pelos Govemos anteriores. Alegaram preocupação com a qualidade de ensino e dos futuros profissionais7. O lob médico funcionou e o MEC passou a adotar em finais de 2017 o discurso de que o Brasil já atingira as metas da OMS de alunos/vagas, que é de cerca de 11.000 por ano o que justificaria a moratória. Então, em abril de 2018 o ministro da educação afirma:

Teremos moratória de cinco anos para que possamos reavaliar todo o quadro de formação médica no Brasil. Isso se faz necessário até porque as metas traçadas com relação à ampliação de médicos no Brasil já foram atingidas. Mais que dobramos 0 número total de faculdades de formação de medicina nos últimos anos, o que significa dizer que há uma presença de formação médica em todas as regiões do Brasil. (MENDONÇA FILHO, MINISTRO DA EDUCAÇÃO).

A medida teve repercussão nacional, atingindo as instituições públicas federais, estaduais e municipais além das IES privadas de todo o país. A ampliação de vagas em cursos de medicina já existentes em instituições federais também ficou suspensa pelo mesmo período. De acordo com o 
então Ministro da Educação Mendonça Filho, a medida se justificava dada a necessidade de realizar uma avaliação e adequação da formação médica no Brasil.

Por seu lado, a Associação Brasileira de Mantenedoras de Ensino Superior (ABMES) reagiu afirmando que a medida fora um retrocesso. Janguiê Diniz argumentou na época que: "Estancar a criação de novas graduações na área não tem qualquer relação com a garantia da qualidade dos serviços prestados e nem dos profissionais que são disponibilizados no mercado de trabalho9."

Esse episódio é emblemático do embate de forças entre Estado, Campo da Medicina e capital e que é uma luta constante, com avanços, retrocessos, viradas de jogo na qual os argumentos politicamente corretos, as preocupações genuinamente sociais são apenas cortina de fumaça para esconder os interesses privados dos grupos envolvidos.

\section{REFERÊNCIAS}

AMARAL, JL. Duzentos Anos de Ensino Médico no Brasil I. Tese (doutorado em Saúde coletiva). Universidade do Estado do Rio de Janeiro, Instituto de Medicina Social. Rio de Janeiro. 2007.

BOLTANSKI, L; ESQUERRE, A. Enrichment, profit, critique. New Left Review, v. 106, 2017.

BOURDIEU, P. What makes a social class? On the theoretical and practical existence of groups. Berkeley Journal of Sociology, n. 32, p. 1-49, 1987.

UNESP, 2004.

Os Usos Sociais da Ciência: por uma sociologia clínica do campo científico. São Paulo:

O Poder Simbólico. Lisboa: Difel, 1989. p. 59-73.

Brasil. Constituição. Constituição da República Federativa do Brasil. Brasília, DF. Senado Federal. Centro Gráfico. 1988.

BUENO, RRL; PIERUCCINI, MC. Abertura de Escolas Médicas no Brasil. Relatório de um cenário sombrio. 2 ed. Associação Médica Brasileira- Conselho Federal de Medicina, 2005.

DIÁRIO OFICIAL DA UNIÃO. N. 66. Sexta-feira, 6 de abril de 2018.

DONNÂNGELO, MCF. Medicina e Sociedade: 0 médico e seu mercado de trabalho. São Paulo: Pioneira, 1975.

DUBET, F. Qual Democratização do Ensino Superior? Cad. CRH, Salvador, v. 28, n. 74, p. 255-266, Agosto. 2015.

GONÇALVES, MB, BENEVIDES-PEREIRA, AMT. Considerações sobre o ensino médico no Brasil: consequências afetivo-emocionais nos estudantes. Rev. bras. educ. med. v. 33, n.3, p. 493-504, jul/set, 2009.

JATENE, AA. Ensino médico no Brasil. Revista USP, n. 100, p. 77-86, 18 fev. 2014 
LAMPERT, JB: Dois séculos de escolas médicas no Brasil e a avaliação do ensino médico no panorama atual e perspectivas. Gaz. méd. Bahia, 2008;78 (Suplemento 1):31-37.

LEBARON, F. La crise de La Croyance Économique. Paris: éditionsducroquant. 2010.

MACHADO, MH. Os Médicos no Brasil: um retrato da realidade. Rio de Janeiro: Fiocruz, 1997.

MINISTÉRIO DA EDUCAÇÃO. Censo da Educação Superior 2017: divulgação dos primeiros resultados. Brasília, DF, DEED-INEP, 2018.

MENDES GONÇALVES, RB. Tecnologia e Organização Social das Práticas de Saúde: Características Tecnológicas do Processo de Trabalho na Rede Estadual de Centros de Saúde de São Paulo. Tese (Doutorado saúde pública), Faculdade de Medicina, Universidade de São Paulo. São Paulo, 1986.

NASCIMENTO SOBRINHO, CL.; NASCIMENTO, MA.; CARVALHO, FM. Transformações no trabalho médico. Revista Brasileira de Educação Médica, Rio de Janeiro, v. 29, n. 2, p. 129-135, maio/ago. 2005.

Pieratoni, CR.; VIANA, Ana. L. Avaliação de Processo na Implementação de Políticas Públicas: a Implantação do Sistema de Informação e Gestão de Recursos Humanos em Saúde (SIG-RHS) no Contexto das Reformas Setoriais. Revista de Saúde Coletiva, Rio de Janeiro, 2003, n.13, v.1, p. 5992.

PIKETTY, T. O Capital no Século XXI. 1. ed. Rio de Janeiro: Intrínseca, 2014.

POLANYI, K. La GranTransformación: losorígenes políticos y económicos de nuestrotiempo. México, D.F: Fondo de Cultura Económica, 2004.

SCHEFFER, MC. et al. Demografia Médica no Brasil (2018). São Paulo, SP: FMUSP, CFM, Cremesp, 2018.

SCHEFFER. MC. et al. Demografia Médica no Brasil (2015). Departamento de Medicina Preventiva, Faculdade de Medicina da USP. Conselho Regional de Medicina do Estado de São Paulo. Conselho Federal de Medicina. São Paulo: 2015.

SCHRAIBER, LB. O Médico e seu Trabalho. Limites da liberdade. São Paulo: Hucitec. 1993.

SOUZA, CAM. Aspectos atuais do ensino médico no Brasil (1977). In: Documentos do Ensino Médico. Ministério da Educação e Cultura. Departamento de Assuntos Universitários. Comissão de Ensino Médico. Imprensa Universitária. Universidade Santa Maria. 2 ed. 1982.

Texto disponível em periódico eletônico; SPOTLIGHT: estatísticas da força de trabalho em saúde. Edição n 8. Outubro de 2009. http://www.who.int/hrh/statistics/ spotlight_8_p.pdf

\section{Notas}

1 Scheffer, M. et al. Demografia Médica no Brasil 2018. São Paulo, SP: FMUSP, CFM, Cremesp, 2018.

2 http://emec.mec.gov.br/

${ }^{3}$ http://emec.mec.gov.br/ 
4 Os dados mais atualizados sobre a abertura e 0 funcionamento de cursos superiores no Brasil também podem ser acessados no site do Governo federal: http://emec.mec.gov.br/

${ }^{5}$ Relatório da OMS, A view of the world's medical schools - Defining new roles, publicado em 2001.

${ }^{6}$ Diário Oficial da União. N. 66. Sexta-feira, 6 de abril de 2018. p. 114.

${ }^{7}$ Entre 2003 e 2004 o MEC também suspendeu a abertura de novos cursos em razão da pressão das entidades de classe médicas existentes no país.

8 http://agenciabrasil.ebc.com.br/educacao/noticia/2018-04/mec-suspende-criacao-de-novos-cursos-de-medicina-por-5-anos . Acesso em 20/01/2020.

9 Janguiê Diniz, diretor presidente da ABMES. Entrevista ao portal g1.globo.com. disponível em https://g1.globo.com/educacao/noticia/governo-federal-vai-suspender-a-abertura-de-novos-cursos-de-medicina-diz-mec.ghtml (17/11/2017). 